\title{
INTERVENÇÃO HISTÓRICO CULTURAL: DIALOGANDO COM PROFESSORES NA ESCOLA
}

\author{
Fabiane Salomão Souza, Irineu Aliprando Tuim Viotto Filho \\ Universidade Estadual Paulista - UNESP, Programa de Pós-graduação em Educação, Presidente Prudente, SP. E-mail: \\ salomaopsico@yahoo.com.br.
}

\begin{abstract}
RESUMO
Este trabalho descreve as opiniões e impressões dos professores de uma escola pública do Sistema Municipal de Educação de Presidente Prudente/SP, a respeito do processo de intervenção realizado na escola. O objetivo da pesquisa foi de criar um espaço de reflexão e discussão coletivo na escola, com intuito de propor novos direcionamentos e formas de enfrentamento, aos problemas que emergem no cotidiano escolar. A pesquisa teve como sujeitos, os professores do ensino fundamental e os gestores da unidade escolar. O processo de intervenção seguiu os fundamentos teóricos da Psicologia histórico-cultural e Pedagogia Histórico-crítica. Os encontros ocorreram nas HTPCs, nos quais foram discutidos temas diversos, escolhidos pelos sujeitos da pesquisa. Os relatos dos professores descrevem que a intervenção possibilitou a construção de um espaço de reflexão e discussão coletivo na escola, com intuito de romper com a culpabilização e patologização dos processos educacionais.
\end{abstract}

Palavras-chave: Educação. Intervenção na escola. Psicologia. Teoria histórico-cultural. Psicologia Histórico-cultural.

HISTORICAL CULTURAL INTERVENTION: DIALOGGING WITH TEACHERS AT SCHOOL

\begin{abstract}
This work describes the opinions and impressions of the teachers of a public school of the Municipal Education System of Presidente Prudente / SP, regarding the intervention process carried out in the school. The objective of the research was to create a space for reflection and collective discussion in the school, with the purpose of proposing new directions and forms of coping, to the problems that emerge in the school everyday. The research had as subjects, the elementary school teachers and the managers of the school unit. The intervention process followed the theoretical foundations of Historical-cultural Psychology and Historical-Critical Pedagogy. The meetings took place in the HTPCs, in which diverse topics were discussed, chosen by the research subjects. The teachers' reports describe that the intervention made possible the construction of a space for reflection and collective discussion in the school, in order to break with the culpability and pathologization of the educational processes.
\end{abstract}

KEYWORDS: Education. Intervention in school. Psychology. Historical-cultural theory. Historicalcultural psychology. 


\section{INTRODUÇÃO}

Este artigo tem o objetivo de descrever as impressões e opiniões dos professores a respeito do processo de intervenção desenvolvido em uma escola pública do Sistema Municipal de Educação de Presidente Prudente/SP. A pesquisa teve como objeto de estudo o processo de intervenção no contexto escolar e seus desdobramentos nas práticas pedagógicas dos professores. Os sujeitos da pesquisa foram os professores do ensino fundamental e os gestores da escola, sendo que a escola localiza-se em bairro periférico, com número elevado de queixas de estudantes com problemas de aprendizagem e baixo desempenho no IDEB (Índice de desenvolvimento educação básica). O processo de intervenção seguiu os pressupostos da Teoria histórico-cultual e Pedagogia histórico-crítica que enfatizam a função específica da escola enquanto transmissora dos conhecimentos sistematizados e a importância das relações sociais e apropriações culturais estabelecidas em seu contexto para o processo de desenvolvimento humano, pois é através da apropriação da cultura construída pela humanidade que o homem se humaniza, como afirmam Saviani (2003), Martins (2013), Saviani e Duarte (2013).

Nas palavras de Saviani (2003, p.13) "o que não é garantido pela natureza tem que ser produzido historicamente pelos homens, e ai se incluem os próprios homens". Desta forma, o autor destaca a importância da educação escolar para o desenvolvimento da humanidade nos homens, pois produz "direta e intencionalmente, em cada indivíduo singular, a humanidade, construída histórica e coletivamente pelo conjunto dos homens".

Temos acompanhado na mídia, em estudos e investigações, que a escola pública brasileira tem enfrentado vários problemas, que segundo Leonardo, Leal e Franco (2014) são antigos e se apresentam com novas roupagens. Sobretudo aqueles relacionados ao cotidiano escolar, tais como a relação professor-aluno, dificuldades no processo de ensino-aprendizagem, tensões causadas pelas avaliações externas, questões relacionadas a formação inicial e continuada dos professores, baixo desempenho escolar dos estudantes, indisciplina, agressividade e violência. Além destes problemas, destacamos o aumento das queixas de estudantes com problemas de aprendizagem, situações que são encaminhadas para avaliação de especialistas em clínicas médicas, psiquiátricas e psicológicas, como também para Centros de atendimento. Concordamos com Souza (2000) que as avaliações realizadas nesses espaços, na sua maioria, centram o diagnóstico nas dificuldades apresentadas pelos estudantes, sem, no entanto, considerar o processo de ensino/aprendizagem e demais determinações deste fenômeno que se apresenta na escola e é impetrado aos estudantes. Entendemos que esta forma reducionista de explicar tais fenômenos, leva a diagnósticos os mais variados e, de certa forma, equivocados, que influenciam de forma direta o processo de medicalização da educação tão presente na atualidade, fortemente criticado por Collares e Moysés (1994, 2013), Asbhar (2012) e Leonardo, Leal e Franco (2014). Diante de todas essas dificuldades que se apresentam na escola pública, surgiu o interesse em realizar uma pesquisa a respeito de um processo de intervenção junto a professores na escola, no sentido de identificar seus desdobramentos nas concepções e práticas pedagógicas dos professores na escola. Os desafios postos no desenvolvimento da pesquisa coincidem com os que nos deparamos diariamente, no encaminhamento das demandas advindas do trabalho realizado junto ao Centro de Avaliação e Acompanhamento (CAA) da Secretaria Municipal de Educação de Presidente Prudente/SP (SEDUC), trabalho realizado por uma equipe interdisciplinar e voltado ao atendimento das escolas municipais de Presidente Prudente/SP. No desenvolvimento das atividades profissionais no CAA, identificamos queixas escolares as mais variadas e voltadas aos estudantes, relacionadas a indisciplina, transtornos comportamentais, desatenção e hiperatividade e também queixas relacionadas a problemas de aprendizagem e ao desenvolvimento cognitivo dos alunos.

Ao constatarmos que problemas educacionais, como a exclusão de crianças do processo de escolarização, a patologização dos processos educacionais e o elevado índice de medicalização, estudados por Patto $(1996)$, Collares e Moysés $(1994,2013)$ e outros autores, ainda fazem parte do 
contexto educacional em nosso país, verificamos a necessidade de uma intervenção no intuito de construir um espaço de reflexão, discussão e ação coletiva, no interior da própria escola, com objetivo de encaminhar outras formas de compreensão e ação diante dos problemas vivenciados pelos professores e gestores. Segundo Machado (1997) tenta-se neste processo, produzir novas significações para fatos antigos.

Machado e Souza (1997) destacam que quando não ocorre a reflexão acerca dos problemas vividos na escola, a tendência é "naturalizar", ou seja, pensar que o que acontece é resultado da natureza das coisas e não da história. Bock (2000) destaca que a naturalização tem servido para justificar concepções dominantes, que passam ser vistas como verdadeiras. Assim, passamos a aceitar tudo como natural, "normal", ficando sem reação diante dos problemas. Segundo Nunes e Viotto Filho (2016) fica claro o quanto a sociedade capitalista reproduz a alienação nas suas relações sociais e institucionais e a escola, por sua vez, também se insere nesse movimento, situação que precisa ser enfrentada pelos sujeitos que participam e edificam a escola diariamente. Os autores salientam, que "muitas práticas pedagógicas, relações entre alunos-alunos, professoresalunos e coordenação/diretoria-aluno, estão reproduzindo preconceitos, exclusão, individualismo, violência física e simbólica, isto é, aspectos ligados diretamente as relações alienadas e alienantes presentes na sociedade capitalista" (NUNES ; VIOTTO FILHO, 2016, p.36), situações e vivências que são reproduzidas no interior da escola. Diante dos problemas que se apresentam na escola pública, realizou-se uma pesquisa acerca do processo de intervenção na escola, com gestores e professores, assim, este trabalho tem o objetivo de descrever os resultados obtidos neste processo, a partir das concepções e opiniões dos sujeitos, contidas no texto produzido por eles.

\section{METODOLOGIA}

O processo de intervenção na escola ocorreu quinzenalmente, em encontros com os professores e gestores, durante as HTPCs, por meio de discussão de temas em grupo e compartilhamento de experiências profissionais. A pesquisa foi autorizada pelo comitê de ética em pesquisa, com número de protocolo 109/2009. Foram realizados encontros durante o ano de 2016, os quais contaram com a participação de professores, diretor e orientador pedagógico da escola. Utilizamos para a coleta de dados, a observação sistemática das atividades realizadas, entrevistas, questionários e um texto escrito pelos professores de avaliação das situações vividas durante o processo de intervenção. Durante o processo de intervenção, as discussões de diferentes temas, escolhidos pelos professores, foram conduzidas pelos autores desse trabalho e membros do GEIPEE-thc, assim como pelos especialistas da equipe do Centro de Avaliação e Acompanhamento (CAA), da Secretaria Municipal de Educação de Presidente Prudente/SP. No primeiro encontro foi feito um levantamento de expectativas a respeito do trabalho a ser realizado e temas de interesse dos professores, sendo que alguns deles foram desenvolvidos de fevereiro até novembro de 2016. Neste artigo iremos apresentar os resultados obtidos do texto de avaliação do processo, escrito pelos professores quando do final das atividades no ano de 2016, destacando as reflexões e críticas sobre o processo de intervenção na escola.

\section{RESULTADOS}

Dos temas escolhidos pelo grupo, foram discutidos o fracasso escolar, a importância da mediação no processo de aprendizagem e desenvolvimento, estratégias de ensino/aprendizagem.

Por meio da leitura coletiva de um caso do livro "A produção do fracasso escolar histórias de submissão e rebeldia", da autora Maria Helena Souza Patto (1996), cada participante destacou aspectos que achou mais importante no caso e conseguiram relacionar problemas de estudantes da escola com o caso do menino estudado por Patto (1996).

O processo de aprendizagem e a importância da mediação foram discutidos em outro encontro e o recurso utilizado para a exposição foi a projeção do filme "A maçã". O grupo 
identificou as dificuldades das personagens do filme e as relacionaram com dificuldades de estudantes da escola. Destacaram a importância da estimulação no processo de ensino/aprendizagem, sendo o professor o principal mediador e responsável por proporcionar experiências novas às crianças para o enriquecimento de seu psiquismo. Os resultados obtidos com estes estudos podem ser verificados nas palavras de uma das professoras do grupo:

Uma das reuniões que me ajudou a refletir e até abrir um debate em sala de aula foi sobre as meninas que eram presas dentro de casa que não entendiam o mundo, conversei com meus alunos sobre isso, que temos que buscar conhecimento e sermos abertos as informações porque tem tanta coisa neste mundo que não conhecemos. Citei um exemplo das rádios que tocam muito sertanejo e funk, que é o que estamos acostumados a escutar com que a mídia nos apresenta, mas há tanta música diferente neste mundo que precisamos buscar conhecê-las e assim também com nossas vidas buscando conhecimento. Ficou claro também a parte de como aprendemos, ou por estímulos, por interesses e assim por diante, as vezes o que é significativo pra mim, não é para o outro pois depende de nossas vivências (Professora A).

Outro tema discutido num dos encontros foi o papel da escola, do professor e seu posicionamento político diante da sociedade, foram feitos questionamentos tais como: que aluno a escola quer formar? Que cidadão a sociedade precisa? Nessa direção, foram abordados fundamentos da Pedagogia histórico-crítica e a especificidade do trabalho educativo. Os resultados obtidos com estas discussões podem ser observados no relato da professora B.

De acordo com a teoria histórico-crítica, o conhecimento é capaz de mudar a vida das pessoas e de transformar a sua realidade. Portanto, o professor deverá sempre ter em mente o questionamento: Que cidadão quero formar? Um sujeito que aceita pacificamente sua realidade ou que construa conhecimentos que lhe possibilite melhorar sua vida e a sociedade em que vive? (Professora B).

Podemos identificar nos relatos dos professores que o objetivo da intervenção de criar um espaço de reflexão e discussão para encaminhar outras formas de compreensão e ação diante dos problemas cotidianos, foi iniciado. A respeito da efetivação deste processo a professora $C$ relata:

É um momento onde todos os professores estão reunidos em busca de um objetivo comum. Muitas vezes nosso trabalho em sala de aula acaba ficando cansativo, não temos tempo para parar e refletir. Esses encontros possibilitaram essa parada para ouvirmos diversas opiniões e fazermos várias trocas, deixando assim nosso trabalho mais direcionado (Professora C).

Destacamos o relato de uma professora, no qual ela descreve que as discussões possibilitaram mudanças de concepções e na prática pedagógica dos professores:

O trabalho da equipe na escola está sendo muito importante para os professores, pois proporciona uma reflexão ampla sobre nosso trabalho em sala de aula. Os temas abordados faz com que tenhamos um olhar diferente em relação a maneira como desenvolvemos nosso trabalho em sala de aula e a forma como lidamos com os alunos.Os temas abordados em cada encontro favorece a troca de experiência entre todos os profissionais envolvidos. É um momento onde nós professores temos a 
oportunidade de expor nossas angústias, ouvir a opinião dos colegas e as orientações do grupo (Professora C).

Assim, considerando o resultado das falas dos professores, fica claro que um processo dessa natureza, se não para a totalidade dos membros do grupo, para grande parte deles, torna-se significativo e possibilita reflexões importantes sobre a escola, o trabalho educativo em sala de aula e outras questões importantes para se pensar na qualidade da educação e na necessidade de sua transformação.

\section{DISCUSSÃO}

Com estes estudos junto a equipe escolar, verificamos que o enfrentamento do fenômeno do fracasso escolar e demais problemas que se apresentam no interior da escola, devem ser objetos de constante reflexão e ação coletiva no interior da escola e que os professores são sujeitos imprescindíveis nesse processo, os quais devem contar com todo o apoio da gestão da escola, sabendo que, mesmo com muito esforço, a esfera de atuação do professor apresenta limites e que nem sempre será possível superar os problemas encontrados, no entanto, ressaltouse a necessidade de enfrentá-los continuamente e que só o trabalho coletivo crítico e consciente poderão contribuir para esse processo, como afirmou Tanamachi (2000). As concepções e opiniões do grupo a respeito do trabalho realizado na escola ressaltam a importância de desenvolver pesquisas e estudos no "chão da escola", junto aos sujeitos que constituem a comunidade escolar.

\section{CONCLUSÃO}

Concordamos com Machado e Souza (1997) ao destacarem a importância da reflexão acerca dos problemas vividos na escola, pois ao contrário a tendência é "naturalizar" e atribuir aos estudantes e seus familiares, exclusivamente as causas, desconsiderando suas muitas determinações. Os relatos dos professores analisados nos oferecem a constatação da necessidade de construção de um espaço coletivo de reflexão e discussão contínua no interior da escola, no sentido de identificar problemas e encaminhar soluções coletivas, rompendo com o ciclo da culpabilização e patologização dos fenômenos escolares, que tem como conseqüência, a medicalização da educação. Concluímos que a proposta de uma intervenção histórico-cultural na escola, envolvendo a participação dos gestores e professores, pensando e trabalhando juntos, pode criar as condições para se transformar situações e relações que encontram-se cristalizadas e que merecem ser superadas, na direção de uma visão crítica de educação, escola e sociedade.

\section{REFERÊNCIAS}

ASBHAR. F.S.F. Novas velhas explicações sobre o fracasso escolar In: Psicologia e educação: perspectivas críticas para a ação psicopedagógica .1. ed. Birigüi, SP : Boreal Editora, 2012.

COLLARES, C. L.; MOYSÉS, M. A. A. A transformação do espaço pedagógico em espaço clínico (A Patologização da Educação). Série Idéias (23), São Paulo, FDE, 25-31. 1994.

COLLARES, C. L.; MOYSÉS, M. A. A Controle e medicalização da infância: controlar é preciso. Número 1 ano 1 . Temas em destaque. 2013.

MACHADO, A. M.; SOUZA, M. P. R. (Orgs.). Psicologia Escolar: em busca de novos rumos. São Paulo: Casa do Psicólogo, 1997. 
LEONARDO, N.S.T.;LEAL, Z.F.R.G.;FRANCO, A.F. (Orgs.). O processo de escolarização e a produção da queixa escolar: reflexões a partir de uma perspectiva crítica em psicologia. Maringá: Eduem, 2014.

MARTINS, L.M. O desenvolvimento do psiquismo humano e a educação escolar- contribuições à luz da psicologia histórico-cultural e da pedagogia histórico-crítica. Campinas: Autores Associados, 2013.

NUNES, R.L.; VIOTTO FILHO, I.A.T. A atividade do jogo e suas implicações para o desenvolvimento da consciência da criança na escola. Curitiba: CRV, 2016.

PATTO, M. H. S. A produção do fracasso escolar: histórias de submissão e rebeldia. São Paulo: Casa do Psicólogo, 1996.

SAVIANI, D. Pedagogia histórico-crítica: primeiras aproximações. Campinas: Autores Associados, 2003.

SAVIANI, D.; DUARTE. N. (Orgs.). Pedagogia histórico-crítica e luta de classes na educação escolar. Campinas, SP: Autores Associados, Coleção polêmicas do nosso tempo. 2012.

BOCK, A.M.B. As influências do Barão de Munchausen na Psicologia da Educação. In: TANAMACHI, E.; PROENÇA, M.; ROCHA,M. (Orgs.) Psicologia e Educação: desafios teórico-práticos. São Paulo, Casa do Psicólogo, 2000. 